\title{
Goracle's Travels: En-Visioning Global Communities for Climate Change in An Inconvenient Truth
}

ALISON VOGELAAR

FRANKLIN COLLEGE

ABSTRACT: The uniquely global phenomenon of climate change requires a radical rethinking of dominant categories of social belonging and responsibility. One barrier facing policy-makers, activists, and scientists alike in their attempts to combat climate change is the lack of a coherent and persuasive discourse of global identification that connects geographically, culturally, and economically diverse communities. This essay explores one successful attempt at creating climate change awareness, Al Gore's 2006 documentary film, An Inconvenient Truth, in terms of its rhetorical appeals to global forms of identification, noting specifically how the film articulates common places wherein the audience might locate more global forms of identity and community.

Keywords: Identification and belonging, globalization, visual rhetoric, climate change

RESUMEN: el fenómeno global el cambio climático requiere una reconceptualización radical de las categorías dominantes de adscripción social y responsabilidad. Uno de los obstáculos con los que se encuentran los legisladores, activistas y científicos en su empeño por combatir el cambio climático consiste en la ausencia de un discurso persuasivo y coherente de identificación global, capaz e apelar a comunidades geográfica, cultural y económicamente diversas. Este artículo explora el documental Una verdad incómoda (2006), una de las manifestaciones exitosas en promover la concienciación sobre el cambio climático, en especial las figuras retóricas encaminadas a conseguir modelos globales de identificación, así como la articulación de tropos que permitan al público conectar con construcciones globales e identidad y comunidad.

Palabras clave: identificación y adscripción, globalización, retórica visual, cambio climático. 
«The climatic world is one world even if politically we are not». Reid Bryson, 1977

The uniquely global phenomenon of climate change requires a radical rethinking of dominant categories of social belonging and responsibility. Indeed neither «local» nor «national» formulations of these constructs can adequately respond to the needs of global social problems like climate change. Following Benedict Anderson's assertion that community is in large part «imagined,» this essay explores how one dominant player in the American discourse of climate change, Al Gore, may have helped his audience imagine more global forms of belonging in the documentary film, An Inconvenient Truth: A Global Warning (Anderson, 1977: 217).

Identity and belonging are complex, multi-dimensional, and variously «based» on place and space, physical and behavioral characteristics, practices, ideologies, and ancestry, among other things. Identity is thus a cultural construct. According to Castells (2009: 117), cultural identification refers to the «existence of specific sets of values and beliefs in which specific human groups recognize themselves». And though it is largely the result of unique geographies and histories, it can be intentionally produced through identity-building projects (Castells, 2009). In this sense, identity is also a construction produced by and through the intentional use of symbols. This point highlights the explicitly political nature of identity and identification of the sort that Foucault spent his life's work unpacking, which is that «subjectivity is a discursive production and thus a function of complexes of power-knowledge» (el-Ojeili and Hayden, 2006: 151). That identification builds communities of shared belief and practices indeed has major implications for politics and politick-ing. As such, identitybuilding is a major project of contemporary policy-makers and activists.

As a discursive construct, nationality is but one story we tell ourselves about who we are, where we come from, and where/among whom we «belong» that has major implications for how we think and act upon our world. In spite of the enduring significance of national and regional identification. ${ }^{1}$ increasingly global processes and phenomena have begun to influence «modes of feeling, thinking, and belonging within and beyond national boundaries», (Schueth, 2005: 239). According to el-Oleili and Hayden (2006), globalization, defined broadly as the extension of relations over the globe, plays a fundamental part in the current «crisis of identification» insomuch as it challenges the modern (and pre-modern) identity constructs upon which our lives are built. Accordingly, «new» global

1. See for example the World Values Survey of the University of Michigan (as cited in Castells, 2009) 
realities, like climate change, evidence a need to both theorize and practice modes of coexistence that are located in new forms of identity, attachment, and belonging (Croucher, 2004).

If indeed, as Mother Teresa said, «the problem with the world is that we draw the circle of our family too small», we would do well to explore identitymaking projects that articulate forms of belonging beyond the wildly persuasive «constructed primordialism» of the nation-state (Croucher, 2004). As an advocacy film about the "planetary emergency of global warming», An Inconvenient Truth is very clearly an identity-building project that seeks to create community around the problem of global warming and is thus an exemplary text through which we might examine the rhetorical construction of global identification (Guggenheim, 2006; Castells, 2009).

Media $^{2}$ are one significant source of «power-making» in a society. According to Castells (2009: 315), in an increasingly mediated world, «people make up their minds according to the images and information they retrieve from communication networks». Media ownership thus has major political and social implications for a society. In the context of the United States, communication networks and channels have become increasingly monopolized resulting in a highly commercialized and homogenized «marketplace» of ideas that has fragmented and dissipated the public sphere. Activists and policy-makers alike have thus begun to explore alternative modes of «power-making». Documentary film is one such medium where the «battle for minds and souls» is being waged through a «battle of images and frames» (Castells, 2009: 194, 302).

\section{An Inconvenient Truth as «Symbolic Token»}

While awareness of, and interest in, climate change has waxed and waned over the past four decades, we have witnessed something of a revolution in both the U.S. and global public spheres following the release of Al Gore's Academy Award-winning, fifth highest-grossing documentary ${ }^{3}$ film An Inconvenient Truth: A Global Warning. Most significantly, the film inspired discourse beyond the technical circles of scientific and political elites and into the public sphere. ${ }^{4}$ This is not to discredit or deny the significance of other political, environmental, and cultural events and artifacts that are also responsible for inspiring discourse,

2. While Castells is referring more specifically to the mass media, his assertion holds no less true for the larger domain of media in general.

3. Following Fahrenheit 9/11, March of the Penguins, Earth and Sicko.

4. The notion that the film won director David Guggenheim an Oscar and is at least partially responsible for winning Gore half of a Nobel Peace Prize says something about its profound impact across discursive spheres. 
but rather to pause and take notice of one significant «symbolic token» in the climate change controversy (Taylor, 2003).

What became An Inconvenient Truth began as a slideshow turned «Keynote presentation» Al Gore began giving following his 2000 Presidential campaign loss. The presentation evolved into a film when, according to Gore:

I was giving my presentation to a group in Los Angeles one evening in the spring of 2005, and afterward, several people came up to me afterward and suggested I consider making a film about global warming. This particular audience included some well-known figures in the entertainment industry, including environmental activist Laurie David and film producer Lawrence Bender, and so I knew their intentions were serious $[\ldots]$

In the documentary film, Gore presents the scientific evidence for global climate change and the consequences that he, and those he cites, believe it will have if the amount of human-generated greenhouse gases is not reduced. In keeping with its original format, the film is enhanced by a plethora of digital presentational aids that show its audiences the effects, realities, and consequences of climate change. The film is also a personal narrative about how Gore became a climate change «believer» and advocate. The film was directed by Davis Guggenheim, produced by Jeff Skoll, Laurie David, Lawrence Bender, Scott Z. Burns, and Leslie Chilcott, written in part and starring Al Gore. The film premiered at the Sundance Film Festival, opened in New York and Los Angeles on May 24, 2006, and was released on DVD in November of the same year. To date, it is the fifth highest grossing documentary in the United States (Mojo, n.d.). And on February 25, 2007, it won «Best Documentary Film» at the 2006 Academy Awards. An Inconvenient Truth is thus an exemplary text through which one might examine the rhetorical construction of global community.

\section{Imagining Global Belonging}

As a documentary film, An Inconvenient Truth is at once image-laden and image-dependent. As such, a critical analysis that attempts to reveal how Gore's film may have constructed a community for climate change requires a conceptual framework for understanding the rhetorical impact of visual images. The emergent focus upon the prominence of visual texts in social meaning making (inspired and facilitated by digital and electronic media) compels social and critical theorists to both remember and rethink the rhetorical significance of the visual. 
In spite of the fact that images have historically played an important role in developing consciousness and sociality, «in Western culture, images have often been placed in a secondary and subordinate relationship to written and verbal texts and the potential dialogy between images and words has been especially neglected», (Hill \& Helmers, 2004: 2). According to Hariman and Lucaites (2003: 364), «visual media have been thought to be either irrelevant or dangerous with respect to democratic deliberation and the public use of reason». Likewise, there is «a perception that the study of images is soft or non-rigorous because images are commonly construed to be illustrative or decorative» (Hill and Helmers, 2004: 2).

Regardless of their status as «emotional», «irrational» or «dangerous» modes of persuasion, images today are very much a part of the «master's» toolbox. Daily doses of television and internet messages attest to the important status of images in selling products and ideas. The dawn of the television marked an important transformation in our society to what DeLuca calls the birth of «image politics»-politics that marshals, if not depends on, the image to create and persuade mass audiences. According to Edwards, «since the development of the mass media, images disseminated in connection with newsworthy events have become attached to the event in the form of cultural remembering», (Edwards, 2004: 179). Add the staggering transformations in both the production and reproduction of images made possible by the internet and digital technologies, and the world (at least many parts of it) has become decidedly image-inundated.

Given their integral place in the making of social meaning, the redefinition of rhetoric to include the image has become one of the key projects of the «new» rhetoric. Hill and Helmers have termed the contemporary interest in visual texts the «pictorial turn» in rhetorical studies (Hill \& Helmers, 2004: 2). According to Foss, visual rhetoric refers both to a communicative act and a theoretical perspective. As a theoretical perspective, visual rhetoric is a «critical-analytic tool [for] approaching and analyzing visual data that highlights the communicative dimensions of images or objects» (Foss, 2004: 306). Rhetorical studies in this vein include general studies in the persuasiveness of the image (Foss, 1992), the role of iconic photography in political meaning making (Hariman \& Lucaites, 2001), the use of public monuments in the (re)construction of public memory (Blair, 2004), the construction of the political and Presidential body (Grindstaff \& DeLuca, 2004), and the use of images in social movements, including feminism (Demos, 2000), the environmental movement (DeLuca, 1999), and nuclear critics (Taylor, 1997: 289-328). The important work of non-rhetoricians including Roland Barthes, Susan Sontag, and Kress and van Leeuwen as well as the work being done in media, cultural and policy studies about the impact of visual images should also be mentioned. 
As ubiquitous producers and reinforcers of «basic attitudes toward life that are frequently not consciously faced», images are important artifacts of inquiry, especially in a digital age marked by the rapid and incessant diffusion of images across our individual and social «screens» (Booth, 1971: 101). In order to investigate the rhetorical appeals to global identification evoked in the film, this essay applies Kress and van Leeuwen's (1996) schema for understanding the production of social relations in visual imagery.

Among their many functions, images produce social interactions and relations among involved participants. Through the use of framing and camera angles, visual images suggest social relations among viewers and objects «that rest on competencies shared by producers and viewers» (Kress and van Leeuwen, 1996: 115). According to Kress and van Leeuwen (1996: 48), images involve two kinds of participants and three relations. Interactive participants are those who «speak and listen or write and read, make images or view them». Represented participants «constitute the subject matter of the communication [...] the people, places and things represented in and by the speech or writing or image[...]». Relations may be created between (1) represented participants, (2) interactive and represented participants and/or (3) interactive participants. As a study in the rhetorical construction of identification and community, this analysis examines the ways in which the image frames and angles encode social relations of power and involvement/detachment that have implications for identification and belonging.

According to Kress and van Leeuwen (1996: 127), the size of the frame can «suggest social relations between the viewer and objects, buildings and landscapes». They assert that at least three mediated distances can be distinguished and that «there are correspondences between these distances and our everyday experience of objects and the environment» (Kress and van Leeuwen, 1996: 127). At close distance, «the object is shown as if the viewer is engaged with it [...]» (Kress and van Leeuwen, 1996: 127). At middle distance (where the object is shown in full but without much space around it), «the object is there for our contemplation only, out of reach, as if on display [...]» (Kress and van Leeuwen, 1996: 127-8). At long distance, the viewer is positioned from a place outside the frame in a way that allows for an impersonal «overview» of the object (Kress and van Leeuwen, 1996).

Camera angles likewise re/produce social relations. According to Kress and van Leeuwen these are achieved through the use of horizontal and vertical angles. The horizontal angle, they assert, «encodes whether the image-producer (and hence [...] the viewer) is 'involved' with the represented participants or not» (Kress and van Leeuwen, 1996: 136). According to the authors, the frontal angle implies: «What you see here is part of our world, something we are involved with» (Kress and van Leeuwen, 1996: 136). The oblique angle, on the 
other hand means: "What you see here is not part of our world; it is their world, something we are not involved with» (Kress and van Leeuwen, 1996: 136). Camera height is also «an important means of expression in cinematography». According to the authors, «a high angle makes the subject look small and insignificant [whereas] a low angle makes it look imposing and awesome». An eye-level angle on the other hand infers an equal relationship between represented and interactive participants (Kress and van Leeuwen, 1996: 140).

The following section uses Kress and van Leeuwen's framework to describe the three scenes within which social relations are conferred and constructed in An Inconvenient Truth as they have implications for identity and community building around the issue of climate change.

\section{Staging Climate Change: Envisioning Spaces of Belonging}

«All the world's a stage»

William Shakespeare

The first and last few minutes of An Inconvenient Truth are poignant as they articulate the literal and symbolic terrain of climate change. The first few moments introduce us to two very different versions of planet Earth: one delicate, vulnerable and touchable, the other powerful, bold, and enigmatic; one local, the other global. One positions the viewer within, the other without. One resembles childhood storybook illustrations, the other something first seen in a science textbook. One is reminiscent of a biblical scene, the other a Star Wars scene. In one we feel. Upon the other we gaze. One is brought to us by Gore the narrator, the other by Gore the presenter. In one we are situated, from the other we are distanced.

These brief moments are rhetorically potent as they attempt to portray Earth in its/her full complexity, as a mutually global and local imaginary and as the ground on which we all stand. In their careful evocation of space/place and belonging, these first few scenes of the film are entangled with the complex new ways that global processes and phenomena like climate change compel us to think about spatial belonging. Whereas the bulk of the film takes us on three interwoven journeys through the climate change phenomenon and history, these short «bookends» instead situate climate change in specific and familiar sites of identification. Sites, I believe, help to set the stage for climate change advocacy by providing rich rhetorical resources for identification and belonging. The following sections examine the rhetorical construction of «nature,» «Earth,» and «Al Gore,» as they are visually mediated as sources of identification and belonging. 


\subsection{Scene One: Human Nature}

«A lake is the landscape's most beautiful and expressive feature. It is Earth's eye; looking into which the beholder measures the depth of his own nature». Henry David Thoreau, Walden

In the first few seconds of An Inconvenient Truth, there is no narration, just a riverbank and the viewer. The foliage on screen is dense and colorful and the water laps in the background with melodic regularity. And then calmly, quietly Al Gore, the scene's narrator, reflects:

You look at that river gently flowing by. You notice the leaves rustling with the wind. You hear the birds; you hear the tree frogs. In the distance you hear a cow. You feel the grass. The mud gives a little bit on the riverbank. It's quiet; it's peaceful. And all of a sudden, it's a gearshift inside you. And it's like taking a deep breath and going, 'Oh yeah, I forgot about this'. (An Inconvenient Truth)

This «Edenic» scene presents a Thoreauvian version of nature - one that is intimate and accessible. Appropriately enough, both Gore's life and this story start in 'Eden,' also known as Carney Fork River, Carthage, Tennessee.

Scene one opens with a close-up shot of tree branches and leaves. The camera pans to the right and we begin to see the river behind the tree. The camera continues to pan to the right and stops for a moment focusing narrowly on a skinny branch and the water in the background. The camera zooms out now to reveal a slightly wider perspective of the river - here we can see more of the river and trees along its bank. The camera shifts to another angle of the river; this one a little further back. The sunlight shimmers on the trees. The camera shifts again; this time over the shallow riverbank. The camera pans for a few moments to the left and we begin to see the riverbank and the trees. Again the sunlight dances on the water; mist hovers on its surface. The sunlight glistens everywhere. The camera pauses here for a few reflective seconds. The scene fades then abruptly to black. The last scene of the film unfolds similarly with the melodic piano music and a close-up of a branch coming out of the water. The camera pans up and left to a tree branch where it pauses momentarily. The scene shifts to a wider shot of the river and the trees on the opposing riverbank and then pans gradually to the left until we see the riverbank at «our feet» and trees to «our side». The camera pauses and the scene fades again gradually to black.

Using the techniques of close shot, frontal and eye-level angles, these opening and closing scenes produce an intimate, involved and equal relationship between the viewer and nature. They are shot at close range so as to simulate the 
experience of being in the scene. The camera hovers at an eye-level angle and scans the scene from that vantage point so as to produce a high level of involvement between the viewer and the scene depicted. The sounds of birds, bugs and water further evoke the experience of actually being in the scene. The scenes are joined by just two outside «voices» - a piano and Al Gore - who also aid in producing this intimate, accessible vision of nature. In both scenes, simple piano chords reverberate in the background. Gore's narration in the first scene highlights the sensory features of the scene. Here he encourages the audience to «look», «notice», «feel», and «hear» as one might in nature. Notably, his narrative does not privilege sight and instead gives equal weight to hearing and feeling. His descriptions are also aesthetic and alive. For example, «the river gently flows», «the leaves rustle», «the mud gives a little», and «you take a deep breath». Conspicuously, humans and any indication of «civilization» are absent in the scenes of the river. Though the camera does pan on a couple occasions to medium shot, a shot that, according Kress and van Leeuwen (1996), intimates social distance, these scenes on the river present a predominantly uncivilized and un-socialized nature.

In one sense, the landscape evoked here is a deeply personal nature that posits a sense of belonging that is fundamentally individual. The intimate and sensorial imagery reinforced by the auditory elements of the scene are experiences located very much in the individual body. Unlike seeing, the senses of hearing and, especially, touch are highly individualized, subjective experiences. This sense of individuality is enhanced by the fact that the scene is occupied by no one but the viewer. Indeed, the camera's eye positions the viewer as the only person embedded in the scene. The scene is also a familiar American «locale» in the sense that it evokes common American scapes associated with the experiences of camping and hiking and even reading and gazing. ${ }^{5}$ This first stage thus, at least partially, evokes a deeply «local» sense of being and belonging situated in the subjective experience of nature, and American visions of nature.

In addition to the subjective/individual sense of belonging evoked in these first and last scenes, there is a more global sensibility transmitted through the language and features of the scene. The scene itself is indistinct. Gore never «names» nor «locates» it in these first and last moments. It is instead presented as a common place that exists somewhere in our collective memory, some place Gore suggests we have forgotten but can (and must) remember. The vision presented is dream-like, a sort of hallucination - it is slightly blurry, the camera pans slowly, sleepily, the natural sounds are quiet and calming, and the music is

5. By reading and gazing, I mean to suggest that even for those who have not directly experienced (i.e. «walked in») such scapes, it is a no less familiar scene. 
restful, like a lullaby. The scene is vague and yet familiar. It is an idealized vision/version of nature and belonging that we can and indeed must, Gore hints, remember. Another poignant feature of these «visions» is the use of the second person plural, «you,» point of view in his narration - a rhetorical device that may evoke a simultaneously global (universal audience) and local (individual viewer) sense of being and belonging in nature. As a rhetorical device, the second person engages «you» in the scene without particularizing the experience, thus creating a scene in the film that is both subjective and collective.

In spite of the potentially egalitarian and ecological inspirations and implications of this vision of belonging, it is not without its own baggage; most significantly in the ways that it is ignorant of the social and material facets of being in nature. As Bergman (1996) suggests, the idealists' escape into nature is in some senses an escape from sociality. And though the relationship it posits between nature and humans is undoubtedly positive and egalitarian, the vision is blind to one very important aspect of being human, which is, being among other humans. At any rate, this important «stage» in the film evokes a rhetorically powerful vision of mutual, universal belonging in nature.

\subsection{Scene Two: Star Gazing}

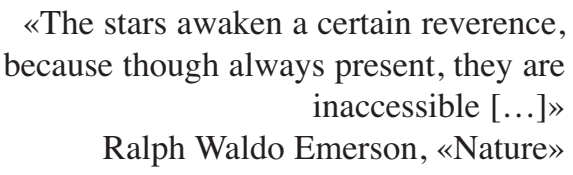

Scene two: Goodbye nature, hello «Earth Rise,» that object of inquiry and site of great scientific mysteries, with its abrupt silence and stoic immobility. Less than two minutes into the film, Gore, the presenter, introduces us to it: Earth - a place, a phenomenon, a photograph. In fact, according to Gore, «the most commonly published photograph in all of history». The photograph is the product of that most coveted and respected of scientific endeavors, space exploration, the science of the final frontier. This is the Earth according to science: Eden after the Enlightenment. It is the Earth we learn about in school - a place about which we learn and wonder, brought to us from a 'space' most of us will never occupy.

This second scene through which Gore articulates climate change contrasts starkly with the first. Whereas the first scene stages climate change within nature, placing the viewer inside the frame and beside the object, this second scene intimates an impersonal, detached, and predominantly hierarchical relationship between the viewer and Earth, positioning the viewer from without 
and below by using impossible perspectives (achievable only by highly technical modes of seeing). Moreover, the varied screens on which the images are depicted in the film are often made transparent - a move that distances the viewer even more from the image because we are made aware of the multiple lenses that both make this image visible and separate us from the «real thing». Unlike «nature», «Earth» is silent, brought to us via imagery alone. In the one video shown by Gore in this scene, Earth is mute - birds, bugs, and water are simply too far away to be heard. In these scenes, Gore describes and historically situates the capture of these images with minimal and yet significant remarks.

In the first and last few moments of the film, we are presented with three iconic images of planet Earth, «Earth Rise», «Blue Marble», and «Pale Blue Dot», images so culturally pervasive and recognizable that they are indeed rich sources of identification among diverse audiences. «Earth Rise» and «The Blue Marble» are dark and bold photographic representations of planet Earth taken from space on the Apollo 8 and 17 missions respectively. In each, continents are visible, but their nuances are indistinguishable. Nations, landscapes, and the built world are invisible. «Earth Rise» is framed by a long, frontal shot that, according to Kress and van Leeuwen (1996), intimates impersonal and objective relations between the viewer and the viewed. It is the frame of science. «The Blue Marble» is framed by a medium, frontal shot that, according to Kress and van Leeuwen (1996), encourages social distance with the object represented. In this sense, Earth is a part of the viewer's social world but not an intimate part of their personal experience. While both of these images are taken from the eyelevel angle, they are presented to the studio audience depicted in the film from a screen that is set above them. So while the images may suggest a sense of equality among viewer and Earth by virtue of being eye-level, the screen through which these powerful images of Earth are mediated may instead create a sense of power over the audience. ${ }^{6}$

By depicting images of Earth on which nations are invisible (too small to see), these visions articulate a source of belonging outside the pervasive and persuasive construct of the «nation-state». In their ignorance of the «Enlightenment invention of continental space and place», these images may also compel viewers to imagine categories of belonging along more global lines (Walcott, 2007: 166). Brought to us from without (i.e. space) and presented from that vantage point, these visions depict the Earth as a whole (rather than in its continental and national parts), and therefore offer only one possible mode of belonging - as Earthlings. Though we can see the outline of the continents on

6. Indeed Kress and van Leeuwen's discussion of the influence of frames and angles on social relations does not account for the multiple screens through which images may now be viewed. 
some of the images, they are but small, green/brown shapes on a blue surface. This vision replaces the «nation as container», metaphor with the «Earth as container» (Held \& McGrew, 2002). Indeed, from space, the only meaningful «us» is Earthling, not Russian, American, Iraqi, or Chinese. Nationality simply does not exist from this vantage point. This is belonging based on shared containment on a very small planet in a very large universe.

As mentioned above, each of these images has achieved the status of «iconic». According to Hariman and Lucaites, iconic images, like «Earth Rise» and «The Blue Marble», ${ }^{7}$ are «images produced in print, electronic, or digital media that are widely recognized, are understood to be representations of historically significant events, activate strong emotional responses, and are reproduced across a range of media, genres, or topics» (Hariman \& Lucaites, 2002: 366). They suggest that iconic photographs in particular are powerful forms of public address insomuch as they «reflect social knowledge and dominant ideologies; they shape understanding of specific events and periods; they influence political action by modeling relationships between civic actors; and they provide figural resources for subsequent communicative action» (Hariman \& Lucaites, 2002: 366). In this sense, iconic images are important tools for identity-building projects.

Iconic images «acquire public appeal and normative power by providing embodied depictions of important abstractions operative within the public discourse of [a] historical period» (Hariman \& Lucaites, 2003: 58). Supporting this function of iconic images, Gore asserts that «Earth Rise» «exploded in the consciousness of human kind», resulting in the manifestation of the contemporary environmental movement, which he suggests took shape just 18 months after the image was photographed and published. Indeed, these «visions» of Earth came at a very poignant moment in both American and «global» history - the Cold War - an anxious episode in human history characterized by the imminent possibility of nuclear war. These images from space, ironically a by-product of the Cold War desire to own and conquer the final frontier, ultimately hinted at the impracticality of nuclear war in their visual representation of our global interconnectedness and, more significantly, our mutual containment on planet Earth. They capture a certain «je ne sais quoi» that was lingering in the air at the time - a hopeful and also terrifying moment of global awareness.

Another important feature of iconic images is their appropriation to new contexts wherein they may function to create analogies among potentially disparate experiences (Edwards, 2004). Whereas these images were first used to

7. Other examples include «The Migrant Mother», «The Flag Raising at Iwo Jima», «Accidental Napalm», and «The Kiss». 
demonstrate the amazing capabilities of the United State's well-funded space program, they very quickly became visual evidence of the problematic nature of nuclear warfare. Their appropriation by the producers of An Inconvenient Truth subtly creates an analogy between the implications of nuclear war and climate change without having to «say» a word. Indeed, a verbal rendition of this metaphor may have proven detrimental and would have at least invited counter-argument. Images like these are, on the other hand, suggestive rather than argumentative and leave the audience to make the (desired) connection.

The images depicted in these first and last moments are introduced as spectacular creations that have been enhanced in a variety of ways so as to privilege and encourage unique, indeed impossible, visions of Earth, visions Gore elaborates upon in his narration. Earth is articulated as a work of art that should be seen as, in Gore's words, beautiful, rare, and magical. By emphasizing Earth's beauty, these images also encourage a form of belonging I might call «collective gazing». The various images of audience members gazing upon these images in the film enhance this collective sense of Earth appreciation. While this form of belonging is productive in the sense that it assumes and requires thinking of ourselves as a collectivity, and a universal one at that, it lacks a form of belonging situated in interaction and sociality. Because of their focal point upon the screen, there is little interaction with or acknowledgement of the other beings in the room. Like the form of belonging constructed in «nature», this collective belonging is also deeply solitary.

In spite of their rhetorically savvy dis-articulation of dominant forms of belonging based on nationality, both these images and Gore are silent when it comes to articulating a new vocabulary for belonging. Rather than simplifying, sublime iconography tends towards complexity and incomprehensibility. And though this is a powerful rhetorical move, insomuch as it destroys the dominant discourse of national belonging, the awe experienced by the presentation of this Earth is more likely to inspire consumerism (e.g. in the form of screen savers, posters, or t-shirts) than activism or conservation.

This is the danger in images that envision a kind of «celebrity» Earth - alarmingly beautiful, larger than life, intriguing, and yet distant, untouchable and ultimately unknowable. Like her People or Look! counterparts, celebrity Earth is a popular «pinup» ironically found on a panoply of consumer junk - $t$-shirts, mugs, mousepads, screensavers, and calendars. Indeed «the purchase and use of pictures and descriptions of the sublime imply that the scenes they depict are ownable and consumable» (Orevac, 1996: 71). By extension, images such as these may create a hyper-reality of their subjects that «reinforce the impression that the environment cannot be substantially damaged by human efforts» (Orevac, 1996: 72). An argument could thus be made that photographic representations depicting Earth in these ways has lent to the belief that (as Gore 
restates in the film) «the world is so big that we can't possibly have any lasting, harmful impact on the Earth's environment».

One of the final images of Earth presented in the film, also considered iconic, offers a slightly different vision of Earth. In «Pale Blue Dot,» an image taken in 1990 by the Voyager I spacecraft when it was four billion miles away from the planet, the Earth is invisible. We see only a beautiful smattering of blue, yellow, pink and red light on a very dark surface. Only when the camera zooms in do we see the object to which Gore wishes to draw our attention: a pale blue dot we quickly learn is planet Earth. From this very different perspective, the Earth is diminutive, one very small dot in a very large universe. While the first, light-smattered image of the universe is quite beautiful, the «little blue Earth» is but a small speck that would hardly be missed by the universe if it disappeared. This moment provides what I believe is one of the most compelling scenes in the film. This stage is quite small and fragile. It imagines «us» as one insignificant dot in a large, dark, and impersonal universe. It is indeed a reality check for those Lilliputians among us. These are scary images that may, according to Beck, produce social solidarity through the perception of common risk. This is a «risk community» (Beck, 2002).

As in the representations of nature, these visions of belonging are not without cultural locations and baggage. They are embedded in sublime and scientific modes of seeing that create an «other worldly» world that is both so profound and yet so unreal that it may seem indestructible and incapable of human harm. Nonetheless, they may help audiences, especially Americans, imagine their common place on Earth and common plight as Earthlings drifting together in one unimaginably large universe.

\subsection{Stage Three: Al Gore, Rock Star}

«Come together right now, over me». The Beatles, «Come Together»

The final surface upon which the film stages climate change is on Gore's own body. Following the representations of nature and Earth which I have just described, the film rhetorically constructs $\mathrm{Al}$ Gore, the man, as a significant site of identification. Whereas he began the film a notoriously dull politician (likened by one commentator to cardboard), the post-An Inconvenient Truth Gore has become a celebrity - nothing short of a «guru», a «rock star,» the «Reverend Al Gore», an «Eco-Messiah», and my favorite, the «Goracle».

In this part of the film, the camera follows Gore from stage-to-stage and seato-shining-sea, where he is depicted in constant motion (e.g. in cars, on planes, 
through walkways and airport terminals, on and off stages) greeting, speaking, and most significantly, being celebrated by hoards of adoring fans. Although there are snippets of speech and applause, these scenes are primarily visually mediated and focus upon Gore's physical presence and movement among and around «the people». In these scenes, Gore's body is predominantly shot at a medium distance and both eye-level and low level angles firmly placing him at a social distance and shifting between equal and hierarchical social relations. This mixture of shots and angles makes him both powerful and accessible - the perfect combination for the creation of a following.

$\mathrm{He}$ is simultaneously very American (we see images of him campaigning for the Presidency) and also «worldly» (we see him presenting in China and among culturally diverse audiences). In these moments, he moves through cultures and places seamlessly. He is welcomed and belongs everywhere he goes. He is presented as a cosmopolitan celebrity, adored by all because he represents all (or so the film projects). These brief moments also don Gore with the power of what Hariman terms the «courtly style», a political style that uses the body as its locus of power (Hariman, 1995). In this sense, Gore masterfully embodies power throughout the film in his gesture, clothing, stature, and micro-movements. And though the scene in the film is brief, it cloaks Gore with an air of cultural authority (and his audience with one of submission) and simultaneous accessibility that may prove powerful in creating a «people».

Celebrity plays a critical role both in this film specifically and in climate change advocacy in general. In addition to Al Gore, American stars such as Leonardo DiCaprio, Melissa Etheridge, and Sheryl Crow have climbed upon the climate change stage. According to Kurzman et al. (2005: 357), «celebrities are the new role models». They are a creation of the cultural industries that involve the «commodification of reputation and the construction of audiences» and the routinization and encouragement of mimicry (Kurzman, 2005: 353). According to the authors, the object of mimicry can include dress and style as well as «aspects of their life conduct» including political and ethical stances (Kurzman, 2005: 357). This «trend to treat celebrities with an unusual amount of deference in public debate» has created a dynamic wherein «celebrities are accorded the chance to speak publicly about political issues, whereas experts on the issues, not to mention average citizens, have far less chance of gaining access to the media,» (West \& Orman, 2003: 358). As a result, «celebrity participation in a political cause, like any elite support, can shift the focus of a movement» (Kurzman, 2005: 358). Celebrity is, as such, front and center in the identity-building projects characteristic of our contemporary era.

Corporeal power and identification may however contain the seeds of their own destruction for they are entirely dependent upon a single human body - a body without which a community disintegrates. Even so, the evocation of Gore's 
own body as the embodiment of the cosmopolitan aesthetic and the locus of climate change community offer an uncommon man around whom the audience might share something in common. While Gore's body is not a physical place that contains the seeds of community quite like nature and Earth, his figure does serve as a rhetorical embodiment of the community he wishes to construct and represent. Gore's body is thus an evocation of the body politic and may as such serve as a «rhetorical locus of [climate] conscience» (Hauser, 2006: 235).

\section{Conclusion and Implications}

Dominant categories of belonging and identification are frequently visually and spatially ascribed and inscribed. This is nowhere more the case than in $A n$ Inconvenient Truth, wherein we are offered three alternative sites of belonging and sources of identification within which audiences might find common ground. Using specific frames and angles to portray «nature», «Earth», and «Al Gore», this film tussles with the complex new forms of identity and community emerging and required in an increasingly global society, while articulating common places (visual scapes) wherein audiences might locate global forms of belonging and identification. This is not to suggest that these sites of identification are without ambiguity and tension. It is however this very complexity and tension that may help explain the film's resonance and diverse appeal across a variety of audiences.

For theorists of globalization and social change, An Inconvenient Truth offers an ideal case study about how key players are attempting to negotiate this new global terrain, and how one film may have succeeded in producing persuasive rhetorical constructs for the more complex forms of belonging required in an era of complex interdependence. While the discourse of nationalism has functioned well to create national cohesion and wealth in the United States and elsewhere, it has proven ill-adept at helping stakeholders (technical and lay) understand and imagine the new terrain and demands of social problems that require global cooperation and participation. Indeed, the discourse of nationalism may be antithetical to truly coming to terms with the ways in which environmental issues, like climate change, erase the significance and possibility of boundaries and borders. As such, this text proffers several examples of belonging that move beyond national modes of belonging.

This film also encourages us to think about the existence and significance of «universal» discourses such as, in this case study, the discourses of science, nature and celebrity. While each of these discourses plays out uniquely in different cultures, they are each a part of the modern project to locate universal ways of thinking, belonging, and connecting - some capitalistic, some idealistic, 
some democratic. As demonstrated in this study, each of these culturally pervasive discourses is evoked as a stage in which An Inconvenient Truth attempts to create community and tell the story of climate change. As culturally pervasive and ideologically powerful discourses, their rhetorical allure is undoubtable. Their appeal asks us however to consider both the possibility and ethical nature of global discourses in a postmodern era. Are they global or are they Western? Should we make an investment in developing and perpetuating global discourses, or is this an imperial project at its core? Which discourses should we create or choose? Can we ethically and meaningfully connect global discourses to local meanings and experiences in ways that honor both the importance of the global and the local? And who is the «we» at the center of this project?

This study has responded to the growing need for examination of the changing dynamics of social identification and belonging in an increasingly global context, specifically as they are mediated and produced in visual texts. Nowhere is this need more evident than in the unbounded phenomenon of climate change. As an international media spectacle, Al Gore's An Inconvenient Truth proffered an ideal case study in emergent attempts to create new forms of identification and community that are responsive to multilateral issues like climate change. In addition to revealing several unique strategies and spaces of identification evoked in the film, this study has advanced the significance of visual approaches to identification and belonging as well as the implications of creating and evoking «global» discourses in the pursuit of mutual understanding and belonging.

\section{Works Cited}

ANDERSON, B. (1983): Imagined Communities, London, Verso.

BECK, U. (2002): «The Terrorist Threat: World Risk Society Revisited», Theory, Culture, Society, 19(4): 1-25.

BlaIR, J. A. (2004): «The Rhetoric of Visual Arguments», in HiLl, C. A.; M. Helmers (eds.) (2004): Defining Visual Rhetorics, Mahwah, Lawrence Erlbaum. 41-62.

BLeIKer, R. (2000): Popular Dissent, Human Agency and Global Politics, Cambridge, Cambridge University Press.

Bergman, C. (1996): "The Curious Peach': Nature and the Language of Desire», in Herndu, C. G.; S. C. Brown (eds.) (1996): Green Culture: Environmental Rhetoric in Contemporary America, Madison, University of Wisconsin Press. 281-303. 
Воотн, W. (2007): «Al Gore, Rock Star», The Washington Post, February 25, A01.

Box Office Mojo (n. d.): «Documentary 1982-present», Box Office Mojo, [accessed May 18, 2008], <http://www.boxofficemojo.com/genres/chart/ ?id=documentary.htm

BurKe, K. (1968): Language as Symbolic Action: Essays on Life, Literature, and Method, Berkeley, University of California Press.

Bryson, R. (1977): «Congressional Testimony, May 26, 1976», United States Congress, 95(1).

Castells, M. (2009): Communication Power, Oxford, Oxford University Press.

Croucher, S. L. (2004): Globalization and Belonging: The Politics of Identity in a Changing World, Lanham, Rowman \& Littlefield Publishers.

Delicath, J. W.; K. M. DeLuca (2003): «Image Events, the Public Sphere, and Argumentative Practice: The Case of Radical Environmental Groups», Argumentation and Advocacy, 17(3): 315-333.

DeLuCA, K. M. (1999): Image Politics: The New Rhetoric of Environmental Activism, New York, The Guildford Press.

DeLuCA, K. M.; A. T. Demos (2000): «Imagining Nature: Watkins, Yosemite and the Birth of Environmentalism», Critical Studies in Mass Communication, 17(3): 241-260.

Demos, A. T. (2000): «The Guerilla Girls' Comic Politics of Subversion», Women's Studies in Communication, 23(2): 133-156.

Edwards, J. L. (2004): «Echoes of Camelot: How Images Construct Memory Through Rhetorical Framing» in HiLl, C. A.; M. Helmers (eds.) (2004): Defining Visual Rhetorics, Mahwah, Lawrence Erlbaum.

El-OJeILI, C.; P. Hayden (2006): Critical Theories of Globalization, New York, Palgrave.

Erickson, K. V. (1998): «Presidential Rhetoric's Visual Turn: Performance Fragments and the Politics of Illusionism», Communication Monographs, 67: 138-157.

Finnegan, C. A. (2000): «Social Engineering, Visual Politics, and the New Deal: FSA Photography in Survey Graphic», Rhetoric and Public Affairs, 3(3): 332-362.

Foss, S. K. (1986): «Ambiguity as Persuasion: The Vietnam Veterans Memorial», Communication Quarterly, 34: 326-340.

- (1994): «A Rhetorical Schema for the Evaluation of Visual Imagery», Communication Studies, 45: 213-224.

- (2004): «Framing the Study of Visual Rhetoric: Toward a Transformation of Rhetorical Theory» in Hill, C. A.; M. Helmers (eds.) (2004): Defining Visual Rhetorics, Mahwah, Lawrence Erlbaum. 303-314.

Gore, A. (2006): An Inconvenient Truth: The Planetary Emergency of Global Warming and What We Can Do About It, New York, Rodale Books. 
- (2007): The Assault on Reason, New York, Penguin Press.

Grindstaff, D. A.; K. M. DeLuCa (2004): «The Corpus of Daniel Pearl», Critical Studies in Media Communication, 21(4): 305-324.

Guggenheim, D. (2006): An Inconvenient Truth: The Planetary Emergency of Global Warming and What We Can Do About It, Paramount. DVD.

Hariman, R. (1986): «Status, Marginality, and Rhetorical Theory», Quarterly Journal of Speech, 81: 291-309.

- (1995): Political Style: The Artistry of Power, Chicago, University of Chicago Press.

Hariman, R.; J. LuCaites (2002): «Performing Civic Identity: The Iconic Photograph of the Flag Raising on Iwo Jima», Quarterly Journal of Speech, 88(4): 363-392.

- (2003): «Public Identity and Collective Memory in U.S. Iconic Photography: The Image of 'Accidental Napalm'», Critical Studies in Media Communication, 20(1): 363-392.

Harris, D.; D. F. Ruggles (2007): Sites Unseen: Landscape and Vision, Pittsburgh, University of Pittsburgh Press.

Hauser, G. A. (2006): «Demonstrative Displays of Dissident Rhetoric: The Case of Prisoner 885/63» in Prelli, L. J. (ed.) (2006): Rhetorics of Display, Columbia, University of South Carolina Press. 229-254.

Held, D.; A. MCGRew (2002): The Global Transformations Reader: An Introduction to the Globalization Debate, Cambridge, Polity Press.

Hill, C. A.; M. Helmers (2004): Defining Visual Rhetorics, Mahwah, Lawrence Erlbaum.

KIEWE, A. (1999): «A Dress Rehearsal for a Presidential Campaign: FDR's Embodied 'Run' for the 1928 Governorship», Southern Communication Journal, 64(2): 155-167.

Kurzman, C. et al. (2005): «Celebrity Status», Sociological Theory, 25(4): 347-367.

KRESS, G.; T. VAN LEEUWEN (1996): Reading Images: The Grammar of Visual Design, London, Routledge.

LAClAU, E.; C. Mouffe (2001): Hegemony and Socialist Strategy: Towards a Radical Democratic Politics, London, Verso.

LEFF, M.; A. SACHS (1990): «Words the most like things: Iconicity and the Rhetorical Text», Western Journal of Speech Communication, 54(3): 252-273.

LuCAITES, J. (1997): «Visualizing 'the people': Individualism vs. Collectivism in 'Let Us Now Praise Famous Men'», Quarterly Journal of Speech, 83(3): 269-88.

LuCaites, J.; R. Hariman (2001): «Visual Rhetoric, Photojournalism, and Democratic Public Culture», Rhetoric Review, 20(1): 37-42. 
Orevac, C. L. (1996): «To Stand Outside Oneself: The Sublime in the Discourse of Natural Scenery», in Cantrill, J. G.; C. L. OrevaC (eds.) (1996): The Symbolic Earth: Discourse and Our Creation of the Environment, Lexington, The University Press of Kentucky. 58-75.

Schueth, S. (2007): «Being at Once National, Global, Other and Between», National Identities, 7(3): 231-239.

TAYloR, B. (1997): «Shooting Downwind: Depicting the Radiated Body in Epidemiology and Documentary Photography», in HusPeK, M.; G. RADFORD (eds.) (1997): Transgressing Discourses, Albany, sunY Press. 289-328.

- (2003): «'Our Bruised Arms Hung up as Monuments’: Nuclear Iconography in Post-Cold War Culture», Critical Studies in Media Communication, 20: 1-34.

Walcott, R. (2007): «The Sight of Sound: The Last Angel of History» in Marchessault, J.; S. Lord (eds.) (2007): Fluid Screens, Expanded Cinema, Toronto, University of Toronto Press.

West, D. M.; J. M. Orman (2003): Celebrity Politics: Real Politics in America, New York, Longman. 